\title{
COVID-19 ile İvmelenen Dijitalleşmenin PLM'e Etkileri
}

\author{
Alim Filik ${ }^{1}$, Rüstem Barış Yeşilay ${ }^{2 *}$
}

\section{ÖZ}

Çalışma kapsamında COVID-19 salgını ile birlikte hız kazanan dijitalleşme trendinin, Ürün Yaşam Döngüsü Yönetimi (PLM) ile olan potansiyel etkileşimi araştırılmıştır. Konuya dair literatür taraması yapılmış, bu kapsamdaki araştırmalar incelenmiş ve neticesinde COVID-19 ile birlikte başlayan süreç içerisinde dijitalleşmenin kuruluşlar için artık kaçınılmaz olduğu ve dijitalleşmenin PLM ile anlamlı olacağına dair bulgular elde edilmiştir. PLM'in ürün yaşam döngüsü fazları açıklanarak, her fazda dijitalleşmenin etkileri açıklanmıştır. Dijitalleşme, dijital ikiz kavramı ve uygulamalarına değinilmiş ve ürün yaşam döngüsünde etkilediği aşamalar açıklanmıştır. Daha sonra, PLM ve dijitalleşme ilişkisinden bahsedilerek, dijitalleşmenin ürün başlangıcı (BOL), ürün ortası (MOL) ve ürün sonu (EOL) aşamalarında olan etkileri açıklanmıștır. Neticede, anlamlı bir dijitalleşmenin PLM ile mümkün olacağı ve dijitalleşme ile PLM'in birbirini tamamlayan kavramlar olduğundan hareketle, COVID - 19 ile başlayan sürecin PLM konseptinin yaygınlaşmasına ve farkındalığının artmasına katkı sağlayacağını ifade etmek mümkündür.

Anahtar Kelimeler: Dijitalleşme, COVID-19, ürün yaşam döngüsü yönetimi (PLM), dijital ikiz

\section{The Impact of Digitalization Accelerated by COVID-19 on PLM}

\begin{abstract}
Within the scope of the study, the potential interaction of the digitalization trend, which accelerated with the COVID-19 epidemic, with Product Life Cycle Management (PLM) was investigated. The literature on the subject has been reviewed, the researches within this scope have been examined and as a result within the process that started with COVID-19, it was found that digitization is now inevitable for organizations and that digitalization will be meaningful with PLM. By explaining the product life cycle phases of PLM, the effects of digitalization in each phase have been explained. Digitalization, the concept of digital twin and its applications are mentioned and the stages it affects in the product life cycle are explained. Then, by mentioning the relationship between PLM and digitalization, the effects of digitalization on the beginning of product (BOL), mid-product (MOL) and end-of-product (EOL) stages are explained. As a result, it is possible to state that a meaningful digitalization will be possible with PLM and that the process starting with COVID - 19 will contribute to the spread of the PLM concept and to increase awareness, since digitalization and PLM are concepts that complement each other.
\end{abstract}

Keywords:Digitalization, COVID-19, product life cycle, management (PLM), digital twin

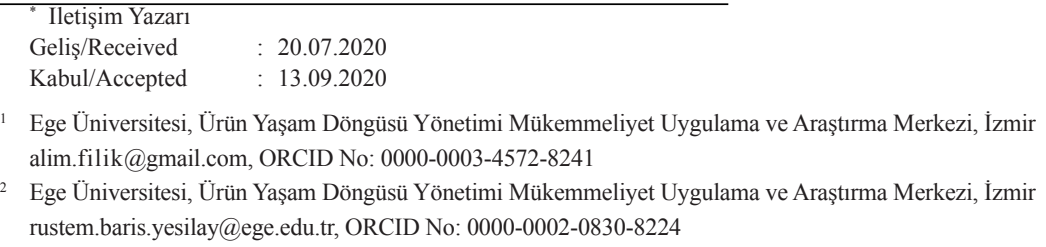




\section{EXTENDED ABSTRACT}

\section{Introduction}

Digitalization has been defined by Gartner as the use of digital technologies to change a business model and create new revenue and value creating opportunities. Digitalization enables improved business process efficiency, quality, and consistency by eliminating manual steps within the company and achieving better accuracy. Digitalization can also provide a better real-time view of operations and results by integrating structured and unstructured data, providing better views on organizational data, and integrating data from other sources.

Product lifecycle management (PLM) allows companies to provide additional value to customers to gain competitive advantage. PLM makes business processes more efficient, flexible, and effective by managing product data generated throughout the product lifecycle. It enables a company to reduce product-related costs and improve product quality, directly increases customer satisfaction, and helps increase market share by shortening time to market.

In this study, considering that digitalization has become a necessity for organizations with the COVID-19 epidemic, evaluations have been made that a meaningful digitalization can be with PLM systems and an efficient PLM system can also be achieved with digitalization.

\section{Objectives}

The main purpose of the study is to explain the importance of digitalization accelerating with COVID-19 and to examine the effects of digitalization on PLM, as well as to reveal that digitalization and PLM are concepts that complement each other. In addition, it is aimed to reveal the effects of digitalization at each stage by explaining the product life cycle stages.

In recent years, there are few academic studies on digitization and PLM. For example, Xin and Ojanen (2017) concluded that with digitalization, the information cycle of the product can be closed and that digitalization will expand the boundaries of traditional PLM, allowing it to be managed throughout the entire life cycle of the product. Tao et al. (2018), who conducted studies on the digital twin and the product life cycle, examined the concepts of the digital twin and the use of the digital twin throughout the product lifecycle. As a result of the literature review, it was concluded that a new publication on this subject would be highly likely to contribute to the literature, since there are few academic studies involving digitalization and PLM issues jointly.

\section{Methods}

Within the scope of the study, existing publications on digitalization, PLM, product life cycle, digital twin and COVID-19 keywords were scanned in English and Turkish. In the literature search on the concepts of digitalization, digital twin and PLM, the relationship between digitalization and PLM is demonstrated by making use of resources such as journals, publications, and related technology sites.

In the section entitled as "COVID-19 and its effects of on digitalization"; McKinsey's digital adoption research and Deloitte's "The Effects of Different Categories of Turkey in the global Covidien-19 Outbreak" reports were examined in detail. Based on the findings in the reports, the increase in the digitalization trend has been tried to be revealed.

\section{Results}

Although the COVID-19 epidemic has great effects on the economy and disrupts the fields of activity in the manufacturing industry, transportation and some production areas with the decrease in human mobility, it is predicted that digitalization will come to the fore in the "new normal". With the COVID-19 pandemic, the transition to digital has accelerated significantly, and many companies consider digitalization as the only option to adapt to competition.

The digital twin has the potential to solve existing problems in PLM with its simultaneous connection between the physical product and the corresponding virtual product. The real-time status data of the product is transferred to the configured virtual product model to realize the simultaneous connection between the physical product and the corresponding virtual product. With the real-time data and historical data obtained, the product manufacturer can understand the working status of the product in real time. With the communication between the physical product and the virtual product, the energy consumption information of the product or important parts can be monitored in real time.

In the study, it has been shown that the product life can be categorized in three important stages. These stages are the beginning of life (BOL) stage, includes conceptualization, definition, and realization; mid-life (MOL) stage, includes the use, maintenance, and service; end of life (EOL) stage includes renewal and reuse of the product, characterized by various scenarios such as dismantling and replacement of parts and reuse and material reclamation. At every stage of the product life cycle, the goals PLM aspires to achieve are different. While the BOL stage aims to improve product design and production quality, the MOL stage is about improving the reliability, availability and sustainability of products. To make PLM a loop and reduce the negative impacts of end-of-use products on the environment and people, it is necessary to address the EOL phase. By moving from BOL to MOL and EOL throughout the entire product lifecycle, the flow of product information is less and less complete, resulting in complex decision-making processes in EOL. However, real-time product life cycle data of each item can be monitored, detected, stored and analyzed with the help of digitalization, especially IoT.

\section{Discussion}

With the COVID-19 epidemic and developing technology, it is possible to state that digitalization is not a choice but a necessity for companies. Within the scope of the study, digitalization, the concept of digital twin and its applications are included and the stages it affects in the product life cycle are explained. Then, by mentioning the relationship between PLM and digitalization, the effects of digitalization on the product start (BOL), mid-product (MOL) and end-of-product (EOL) stages are explained. Therefore, it is possible to state that a meaningful digitalization will be possible with PLM and that the process starting with COVID-19 is an opportunity for the spread and awareness of the PLM concept, since digitalization and PLM are concepts that complement each other.

With the "new normal" after COVID-19, it can be evaluated that companies that are delayed in using digital channels will be greatly disadvantaged. Currently, the impact of digitalization on PLM continues, and companies need to take some steps to keep themselves competitive in the digital age. Nowadays, many actors interacting with the product during the MOL and EOL phase only carry out their respective activities by exchanging little information with other actors. In addition, with digitalization, a holistic exchange of information and interaction between different elements such as designers, manufacturers, customers and recyclers is encouraged.

The study concluded that the digital twin has a high potential application in product design, product manufacturing, and product service to solve problems in the product life cycle. With digitalization, the complexity of products and processes increases, and the data volume becomes extremely large. PLM enables the efficient processing of vast amounts of data. With the applications of digitalization and digital twins, manufacturing firms and interested parties will increasingly be interconnected in both the cyber and physical world.

In the further studies, researchers are recommended to conduct industry-focused case studies showing the interaction of digitalization and PLM. 


\section{GÍRIŞ}

Dijitalleşme, COVID-19 salgınının etkisi ile daha sık duyar olduğumuz bir kavram haline gelmeye başlamıştır. Dijitalleşme, bir iş modelini değiştirmek, yeni gelir ve değer yaratan firsatlar sunmak için dijital teknolojilerin kullanılması şeklinde tanımlanmıştır [1]. Giderek karmaşıklaşan dijital iş ekosisteminde rekabet avantajı elde etmek için, şirketlerinin ürün yaşam döngüsü (PLC) boyunca somut ürünler satmanın yanı sıra ürünle ilgili hizmetler sunması gerekir [2]. Aynı zamanda, ürünlerin ve ortamlarının karmaşıklığı artmakta, bu da ürünü PLC'de farklı şirketler arasında konuşlandırılmış çok disiplinli ekiplerle modellemek için dijital araçları kullanma ihtiyacına yol açmaktadır [3]. Dijitalleştirme, şirketin dahili ve harici verilerini entegre ederek, operasyonların ve sonuçların gerçek zamanlı daha iyi bir görünümünü sağlar ve iş süreci verimliliğini, kalitesini ve tutarlılığını iyileştirir. Dijitalleşmenin şirket içi verimlilik açısından potansiyel faydaları arasında, manuel adımları ortadan kaldırarak ve daha iyi doğruluk elde ederek gelişmiş iş süreci verimliliği, kalite ve tutarlılık yer alır. Dijitalleştirme ayrıca yapılandırılmış ve yapılandırılmamış verileri entegre ederek, organizasyon verileri hakkında daha iyi görünümler sağlayarak ve diğer kaynaklardan gelen verileri entegre ederek operasyon ve sonuçlar hakkında daha iyi bir gerçek zamanlı görünüm sağlayabilir [4].

Ürün yaşam döngüsü yönetimi (PLM) ise, şirketlerin rekabet avantajı elde etmeleri için müşterilere ek değerler sağlamasına olanak tanır [5]. PLM, ürün yaşam döngüsü genelinde oluşturulan ürün verilerini yöneterek iş süreçlerini daha verimli, esnek ve etkili hale getirir [6]. Bir şirketin ürünle ilgili maliyetleri düşürmesini ve ürün kalitesini iyileştirmesini sağlar, müşteri memnuniyetini doğrudan arttırır ve pazara çıkma süresini kısaltarak pazar payını arttırmasına yardımcı olur [7].

Bu çalışmada, COVID-19 salgınıyla dijitalleşmenin artık kuruluşlar için bir zorunluluk olmaya başladığı, anlamlı bir dijitalleşmenin ürün yaşam döngüsü yönetimi (PLM) sistemleriyle olabileceği ve aynı zamanda verimli bir PLM sisteminin de dijitalleşme ile olacağı hakkında değerlendirmeler yapılmıştır.

Çalışmada öncelikle yapılan masa başı araştırması ve literatür taraması ile elde edilen bulgulara yer verilmiştir. Daha sonra, COVID-19 salgınının dijitalleşme üzerine etkileri incelenmiştir. Dijitalleşme ve dijital ikiz kavramları açıklanarak ürün yaşam döngüsü kapsamındaki örneklere yer verilmiştir. Takibinde PLM kavramı açıklanmış ve PLM sistemlerinde dijitalleşmenin etkileri hakkında bilgiler verilmiştir. Son bölümde ise çalışma kapsamında elde edilen sonuçlara yer verilmiştir.

\section{YÖNTEM}

Çalışma kapsamında yapılan masa başı araştırmasında dijitalleşme, PLM, ürün yaşam döngüsü, dijital ikiz ve COVID-19 anahtar kelimelerine dair var olan yayınlar 
İngilizce ve Türkçe olarak taranmıştır. Dijitalleşme, dijital ikiz ve PLM kavramları ile ilgili literatür araştırmasında, dergiler, yayınlar ve ilgili teknoloji siteleri gibi kaynaklardan faydalanılarak dijitalleşme ve PLM arasındaki ilişki gösterilmektedir. Çalışmanın COVID-19 ve dijitalleşme üzerine etkileri bölümünde ise, McKinsey'in dijital benimsenme araştırması ve Deloitte’ın “Küresel COVID-19 Salgınının Türkiye'de Farklı Kategorilere Etkileri” raporlarındaki bulgulardan hareketle dijitalleşme trendindeki artış ortaya konulmuştur [8] [9].

Son yıllarda dijitalleşme ve PLM konularını içeren az da olsa akademik çalışmalar mevcuttur. Örneğin, Xin ve Ojanen (2017) dijitalleşme ile ürünün bilgi çevriminin kapatılabileceği ve dijitalleşme ile geleneksel PLM'in sınırlarının genişleyerek ürünün tüm yaşam döngüsü boyunca yönetilmesine olanak vereceği sonuçlarına varmışlardır [7]. Dijital ikiz ve ürün yaşam döngüsü üzerine çalışmalar yapan Tao ve arkadaşları ise (2018) dijital ikiz kavramları ve dijital ikizin ürün yaşam döngüsü boyunca kullanımı kavramlarını incelemişlerdir [10].

Literatür taraması neticesinde dijitalleşme ve PLM konularını ortak olarak içeren akademik çalışmaların az olması nedeniyle bu konuda yapılacak yeni bir yayının literatüre katkı sunma olasılığının yüksek olabileceği sonucuna varılmıştır. Bu bulgudan hareketle çalışmanın temel amacı COVID-19 ile dijitalleşmenin önemini açıklamak ve dijitalleşmenin PLM'e olan etkilerini incelemek, aynı zamanda dijitalleşme ve PLM'in birbirini tamamlayan kavramlar olduğunu ortaya koymaktır. Ayrıca ürün yaşam döngüsü aşamaları açıklanarak her bir aşamadaki dijitalleşmenin etkilerinin ortaya konulması amaçlanmıştır.

Çalışmanın kısıtları ise dijitalleşme ve PLM ortak paydasında yapılan akademik çalışmaların az sayıda olması, dijitalleşme kavramının literatürde kabul edilmiş ortak bir tanımı olmaması ve ürün yaşam döngüsü yönetiminde yaşamın ortası (MOL) ve yaşamın sonu (EOL) aşamalarında yeterli veri toplanamamasıdır.

\section{COVID-19 SALGINININ DİJITALLEŞME ÜZERİNE ETKILERİ}

COVID-19 salgını ekonomiler üzerinde büyük etkiler yaratmıştır. İmalat sanayi, ulaştırma, insan hareketliliğindeki azalma ile bazı üretim alanlarındaki faaliyet alanları salgınla birlikte sekteye uğrasa da yeni oluşan düzende dijitalleşmenin öne çıkacağ tahmin edilmektedir. Deloitte'ın Türkiye genelinde yaptığ 1 COVID-19 salgınının farklı kategorilere etkisi raporunda en yüksek pozitif etkilenen kategoriler uzaktan eğitim ve çalışma, fitness uygulamaları, mobil perakende, ulusal market zincirleri şeklinde sıralanmıştır. Bu raporda e-ticaret ve dijitalleşme alanlarında erken yatırım yapmış, yetkin insan kaynağı ve özgün deneyimi olan sektörlerin ve firmaların, yatırımlarının karşılı̆̆ını aldığı belirtilmiştir [9]. 
İnsan faktörünü azaltacak yapay zekâ ve robotikle ilgili teknolojiler ile dijitalleşmenin eğitim ve kamudan başlayarak üretim, hizmet ve finans gibi sektörlerde de hızla yayılması beklenmektedir. COVID-19 salgını ile dijitale geçiş önemli ölçüde hızlanmıştır ve birçok firma rekabete uyum sağlamak için dijitalleşmeyi tek seçenek olarak değerlendirmektedir.

Bankalar uzaktan satış ve servis ekiplerine geçerek, krediler için esnek ödeme düzenlemeleri yapmak üzere müşterilere dijital erişim başlatmıştır. Marketler çevrimiçi sipariş ve teslimatlara yönelmiştir. Birçok bölgedeki okullar yüzde yüz çevrimiçi öğrenme ve dijital sınıflara dönüşmüştür. Üreticiler fabrika ve tedarik zincirleri için dijital planlar gerçekleştirmiştir. Listeye daha birçok sektör eklenebilir [11].

Müşterilerin davranışları ve tercih ettikleri iletişim yolları değişmiştir ve dijital kanalların kullanımı artmıştır. Dijital kanalları ilk kez kullanan kişilerin yüzde 75'i "normale" dönüş olduğunda da bu kanalları kullanmaya devam edeceğini belirtmektedir [11]. Çin örneğinde, rekabet halinde olan şirketlerin rekabetteki üstünlüklerini sürdürebilmeleri için dijital kanallarda rakip firmalardan daha başarılı olması gerektiği sonucuna ulaşılmaktadır [12].

Şekil 1'de McKinsey'in Amerikan tüketicileriyle yaptığı dijital benimsenme araştırmasının Nisan 2020 raporunda salgın süresince bankacılık, eğlence sektörü, market gibi dijital kanalları ilk kez kullanan kullanıcıların salgından sonra da bu dijital kanalları kullanacakları gösterilmektedir [8]. Gerçekten de son veriler salgın sonrası 2020 yılının Mart ve Nisan aylarını kapsayan yaklaşık sekiz hafta içerisinde tüketici ve iş dünyasında dijital benimseme oranının beş yıl sonra ulaşılabileceği tahmin edilen seviyeye şimdiden ulaşıldığını göstermiştir [11].

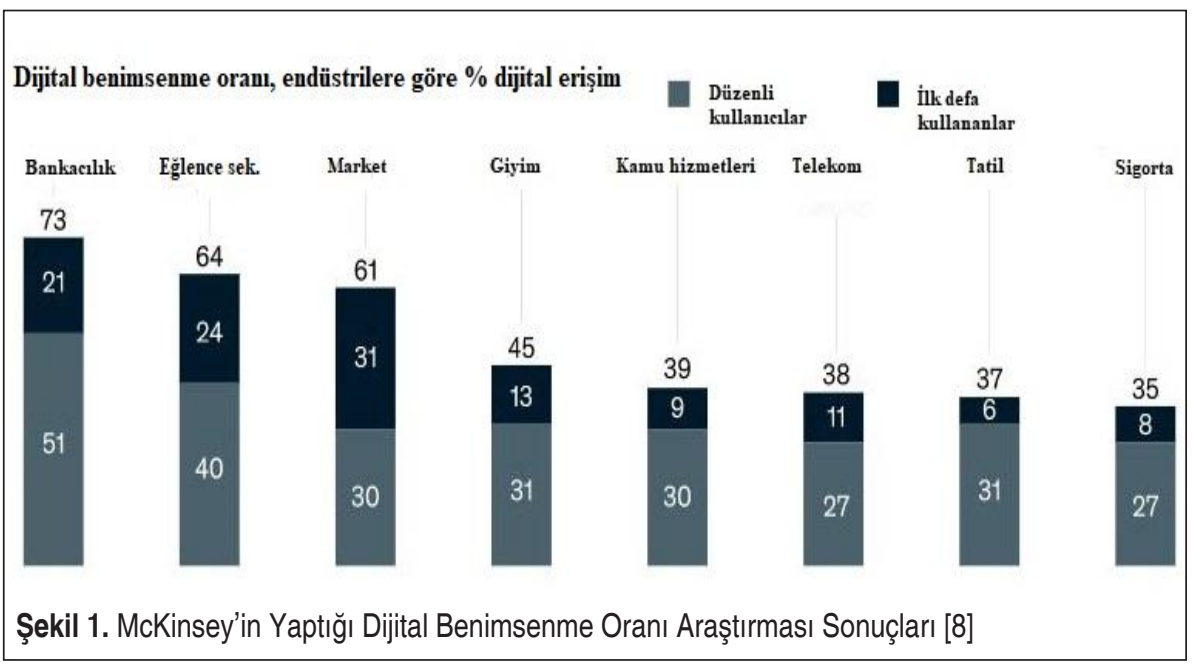




\section{DİJiTALLEŞME VE ETKİLENDİĞİ ALANLAR}

Dijital Dönüşümün 4 seviyesi bulunur. İlk seviye, yeniden etiketleme, var olan bir ürünü dijital olarak ele alma ve bunu dijital dönüşüm olarak adlandırmayla ilgilidir. Seviye 2, mevcut bir bilgi teknolojisi ürününe yeni özellik ve işlevlerin eklenmesi ve dijital dönüşüm olarak adlandırılmasıdır. Seviye 3, dijital dönüşümün mevcut bir şirkete uygulanması diğer bir deyişle şirketi değiş̧irmekle ilgilidir. Ancak bu sadece yeni dijital teknolojilerin ve hizmetlerin uygulanması nedeniyle değil bu teknolojileri kullanılarak şirkette yeni bir iş modeli oluşturulmasıdır. 4. Seviyedeki dijital dönüşüm ise internet, veri tabanı teknolojisi, GPS veya telekomünikasyon gibi bilgi teknolojileri kullanmadan mümkün olmayacak yeni bir iş alanı veya şirketin oluşturulmasıdır. Amazon, Google, Uber, Facebook ve Linkedin gibi şirketlerin oluşmasına neden olan bu seviyedeki dijital dönüşümdür [13].

Üretim açısından dijitalleşme, ürünleri dijital formda tasarlamak, ürünü gerçekten üretmeden hemen önce bileşenleri oluşturmak ve kullanmak ve ürün, kullanıcılar ve üretici şirket arasındaki ilişkiyi sürdürmek olarak tanımlanabilir [14]. Daha çok iş hayatına odaklanan Gartner, dijitalleşmeyi "bir iş modelini değiştirmek ve yeni gelir ve değer yaratan firsatlar sunmak için dijital teknolojilerin kullanılması" olarak tanımlamaktadır [1]. Genel olarak dijitalleşme, dijital teknolojilerin bir şirketin iş modelinde, ürünlerinde, süreçlerinde ve organizasyon yapısında meydana getirebileceği değişikliklerle ilgilidir [14].

\section{DİJITTAL İKİZ VE ÜRÜN YAŞAM DÖNGÜSÜ}

Dijital ikiz kavramı ilk olarak Grieves tarafindan 2003 yllında Michigan Üniversitesi'nde PLM hakkındaki sunumunda yer almıştır. "Dijital İkiz, mikro atom seviyesinden makro geometrik seviyeye kadar potansiyel veya gerçek fiziksel olarak üretilmiş bir ürünü tam olarak tanımlayan bir dizi sanal bilgi yapısıdır. İdeal olarak, fiziksel olarak üretilmiş bir ürünün incelenmesinden elde edilebilecek herhangi bir bilgi dijital ikizinden elde edilebilir" [15], "Dijital ikiz, ürün yaşam döngüsündeki tüm bileşenlerin fiziksel veriler, sanal veriler ve aralarındaki etkileşim verileri kullanılarak gerçek bir eşleştirilmesidir" [10], "Fiziksel bir nesnenin veya sistemin yaşam döngüsü boyunca, anlama, öğrenme ve akıl yürütmeyi sağlamak için gerçek zamanlı verileri kullanarak dinamik bir sanal temsili" [16] şeklinde farklı tanımları mevcuttur. Dijital ikizin fiziksel ürün, sanal ürün ve fiziksel ve sanal ürünü birbirine bağlayan veriler olarak üç bölümden oluştuğunu söyleyebiliriz.

Dijital ikiz kavramı önerildiğinden beri endüstrinin birçok alanında uygulanmıştır ve uygulanmaya devam etmektedir. ABD Hava Kuvvetleri Araştırma Laboratuvarı Yapısal Bilimler Merkezi, gerçekçi bir yüksek doğrulukla uçuş modeli oluşturmak ve sanal model verilerini fiziksel verilerle birleştirerek daha doğru bir yorulma ömrü tahmini 


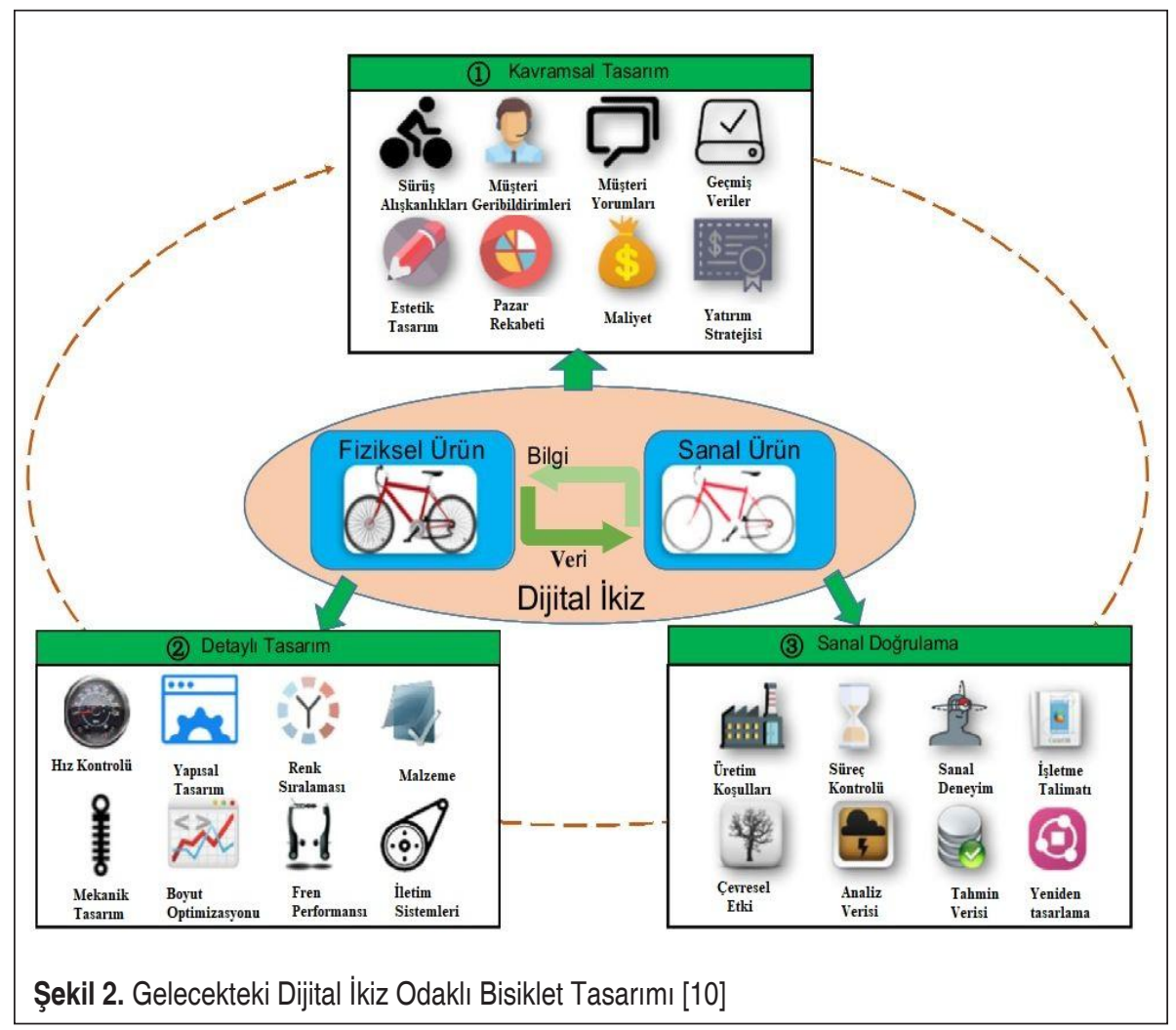

yapmak için dijital ikiz kullanmıştır [17]. Hava Kuvvetleri Araştırma Laboratuvarı, modelin çeşitli verileri entegre ettiği ve birleşmiş aero termoelastik problem için aerotermal model tahminlerine olan güveni simüle etmek ve değerlendirmek için fiziksel alana yüksek düzeyde bağlı olduğu bir çerçeve oluşturmuştur [18]. Cerrone ve ekibi dijital ikiz örneklerin modelini oluşturmuş ve çatlak yolu belirsizliğini çözmek için simülasyon uygulamasını yapmışlardır. Simülasyon sonucu, dijital ikiz kullanmanın kesme yüklemesi altında yanlış tahmini azaltabildiğini göstermektedir [19]. Ayrıca, PTC, Dassault Systèmes, Siemens PLM gibi firmalar ürün tasarım sürecinde, dijital ikiz uygulamasına büyük ilgi göstermektedir [20]. Dijital ikiz, fiziksel ürün ve karşılık gelen sanal ürün arasındaki eşzamanlı bağlantısı ile PLM'deki mevcut problemleri çözme potansiyeline sahiptir.

Şekil 2'de bir bisiklet tasarımının kavramsal tasarım, detaylı tasarım ve sanal doğrulama ile üç aşamadaki dijital ikiz odaklı tasarım süreci sunulmuştur. Ürün tasarım süreci geleneksel olarak, bireyin mesleki bilgi ve deneyimini merkeze alır. Bu durumda, tasarımcılar tasarım aşamasında tasarımın geçerliliğini ve kullanılabilirliğini sürekli olarak kanıtlamak için çeşitli testler yapmalıdır. Buna karşılık, modern ürün tasarımı, 
müşterileri merkez haline getirme ve müşterilerin katılımını artırma yönündeki giderek artan bir eğilime dönüşmektedir. Ayrıca, ürün tasarım süreci giderek daha fazla sanallaştırma, iş birliği ve görselleşmeye doğru yönelmiştir. Dijital ikiz, ürünün her türlü fiziksel verisini sanal bir alana doğru şekilde eşleyebilir. Sanal ürün, ilgili fiziksel ürünün tüm yaşam döngüsü sürecini yansıtabilir. Dijital ikizlere dayanarak, ürün tasarım süreci kavramsal tasarım, ayrıntılı tasarım ve sanal doğrulamaya ayrılabilir [10].

Kavramsal tasarım, tüm ürünün gelecekteki tasarım yönünü belirlemesi açısından ürün tasarım sürecinin ilk ve en önemli adımıdır. Bu aşamada, tasarımcılar yeni ürünün konseptini, estetiğini ve ana işlevlerini tanımlamalıdır. Tasarımcıların bu aşamada müşteri memnuniyeti, ürün satışları, ürün rekabet edebilirliği, yatırım planları ve diğer birçok bilgi gibi çeşitli verilerle ilgilenmeleri gerekir. Bu veriler çok büyük ve dağınıktır, bu da tasarımcıların verilerle verimli şekilde çalışmasını zorlaştırır. Tasarımc1lar ürünün fiziksel alanına her türlü veriyi entegre edebilen ve tüm bilgileri kolayca entegre edebilen dijital ikizleri kullanarak, nerede iyileştirilme yapılması gerektiğini hızlıca anlayabilirler. Dahası, dijital ikiz fiziksel ürünün gerçek zamanlı aktarım verilerini kullanarak müşteriler ve tasarımcılar arasındaki iletişimi daha şeffaf ve hızlı hale getirebilir. Müşterilerin geri bildirimlerini ve müşterilerin önceki neslin kullanımında ortaya çıkan çeşitli sorunları yeni ürünün geliştirilmesinde dikkate almalarını sağlayarak daha doğru bir tasarım oluşturmalarına rehberlik edebilir.

Kavramsal tasarımı bitirdikten sonra, bir sonraki aşama detaylı tasarımdır. Bu aşamada tasarımcılar, ürün prototipinin tasarımını ve yapımını ve ticari üretimde kullanılan araç ve gereçlerin geliştirilmesini tamamlamalıdır. Tasarımcılar, önceki aşamaya göre ürün fonksiyonları, görünüm, ürün konfigürasyonu, tasarım parametreleri ve test verilerini içeren ürün tasarım şemasını daha da geliştirmelidir. Ayrıntılı tasarım aşaması, ürün prototipinin istenen performansı elde etmesini sağlamak için tekrarlanan simülasyon testleri gerektirir. Bununla birlikte, gerçek zamanlı veri ve çevreden etkilenen veri eksikliği nedeniyle, simülasyon testlerinin etkisi açık değildir. Buna rağmen, dijital ikiz teknolojisi bu problemi fiziksel nesnelerin tüm yaşam döngüsünde olduğu gibi çözebilir. Ürünün tüm verilerini ve çevrenin etkisini kaydedebilir [21].

Son aşama sanal doğrulamadır. Geleneksel modelde, tasarımın geçerliliği ve fizibilitesi, ürün tasarımı bittikten sonra seri üretim yapılana kadar değerlendirilemez. Sadece üretim döngüsünü uzatmakla kalmayacak, aynı zamanda zaman ve maliyeti de büyük ölçüde artıracaktır. Tasarımcılar dijital ikiz modeli kullanmayı tercih ederse, herhangi bir bileşenin kalitesi, doğrudan dijital ikiz modelinde hata ayıklama ve tahmin yoluyla üretilmeden önce tahmin edilir. Dijital ikiz sanal doğrulama, ekipman, çevre, malzeme, müşterilerin özellikleri ve geçmiş verilerden tam olarak yararlanabilir. $\mathrm{Bu}$ yöntem, bir tasarım hatası olup olmadığını test edebilir ve bunun nedenini bulabilir ve daha sonra yeniden tasarım daha hızlı ve verimli olacaktır [10]

Ayrıca, doğrulama ve testlerden kaçınarak tasarım verimliliğini büyük ölçüde artırabi- 
lir. Dahası, dijital ikiz sadece davranışları tanımlamakla kalmaz, aynı zamanda gerçek sistemle ilgili çözümler de önerir. Bir diğer ifade ile sanal modelleri temel alan fiziksel nesneleri tahmin etmek için işlem ve hizmet sağlayabilir. Bu nedenle, tasarımcılar dijital ikiz teknolojisini kullanarak, prototipler üzerinde simülasyon testlerini etkili bir şekilde uygulamak ve fiziksel ürünlerin gerçek performansını mümkün olduğunca doğru bir şekilde tahmin etmek için canlı simülasyon senaryoları oluşturabilirler [21].

Ürün servisi, ürün kullanımı ve bakım aşamaları dâhil olmak üzere satış sonrası aşamaları ifade eder. Kullanıcılar esas olarak ürünün güvenilirliği ve rahatlığı ile ilgilenirken, üreticiler esas olarak gerçek zamanlı ürün çalışma durumu, sürdürülebilirlik, ne zaman bakım yapılacak, hangi stratejileri kullanacakları vb. ile ilgilenir. Uçak, otomobil ve elektrik güç ekipmanı gibi karmaşık ürünler için, kusurlardan ve hasarlardan herhangi biri, ürünün gereksiz yere arızalanmasına neden olabilir. Bu nedenle, karmaşık ürünlerin günlük bakımının yapılması özellikle önemlidir. Bununla birlikte, geleneksel yaklaşımlar proaktif olmaktan ziyade reaktif olma eğilimindedir ve çoğu zaman sezgisel deneyime dayanır. Dijital ikiz yöntemi ile arızalar ve anormal gelişen olaylar anlaşılabilir ve önceden bilinmeyen sorunlar öngörülebilir [22].

Dijital ikiz metodolojisine dayanarak, fiziksel ürünün ikizini gerçek zamanlı olarak güncellemek için gelişmiş sensör ve iletişim teknolojisi kullanılmaktadır. Ürünün gerçek zamanlı durum verileri, fiziksel ürün ile karşılık gelen sanal ürün arasındaki eşzamanlı bağlantıyı gerçekleştirmek için yapılandırılmış sanal ürün modeline aktarılır. Gerçek zamanlı durum verileri, ürün konum bilgileri, enerji tüketim bilgileri, kullanıcı çalışması ve ayar verileri, ürün çalışma bilgileri, malzeme yapısı bilgileri, parça aşınma bilgileri vb. içerir. Elde edilen gerçek zamanlı veriler ve geçmiş verileri ile ürün üreticisi, ürünün çalışma durumunu gerçek zamanlı olarak anlayabilir [19].

Fiziksel ürün ile sanal ürün arasındaki iletişim ile ürün veya önemli parçaların enerji tüketimi bilgileri gerçek zamanlı olarak izlenebilir. Gerçek zamanlı ve geçmiş enerji tüketimi verilerine dayanarak, her bir parçanın enerji tüketim oranı, gün / hafta / ay başına enerji tüketimi gibi ilgili istatistiksel analizler yapılabilir. Ayrıca, tahmin algoritması kütüphanesi ve bilgi kütüphanesi ile gelecekteki enerji tüketimi de öngörülebilir. Enerji tüketimi analizi ve tahmini dikkate alındığında, PLM'in sürdürülebilir malzeme seçimi ve büyük ölçekli süreç planlaması gibi ilgili faaliyetleri gerçekleştirilebilir [23].

Dijital ikiz teknolojisi ile yüksek kaliteli sanal ürün modeli, parçaların mekanik yap1sını ve birbirleri arasındaki bağlantıyı tam yansıtabilir. Bir arıza meydana geldiğinde, arızalı parça ürün arıza analizi servisi ile tespit edilebilir. Daha sonra imalatçıya ve kullanıcılara, hatalı parçanın konumu, ilgili sökme sırası, değiştirilmesi gereken parça özellikleri gibi ilgili bakım stratejisi sağlanabilir [10].

Sanal bakım, yapılandırılmış yüksek kaliteli sanal ürün modeli ve sanal gerçekçilik teknolojisi ile uygulanabilir. Ürün arızası meydana gelirken ve bakım stratejisi sağ- 
lanırken, kullanıcılar veya üretici, pratik bakım yapmadan önce sanal gerçeklik ve artırılmış gerçeklik teknolojisine dayalı sanal bakım gerçekleştirebilir [24].

Dijital ikiz odaklı ürün hizmetinin gelecekteki uygulama modlarından birini göstermek için bir güç transformatörü örnek olarak verilebilir. Güç transformatörüne sensörler eklenerek, fiziksel güç transformatörünün gerçek durum verileri sanal modele tamamen senkronize edilebilir. Dijital ikiz, mevcut performans durumuna ve bilgiye göre bakım gerekip gerekmediğini, bir sonraki görevi yerine getirip getiremeyeceğini zamanında analiz edebilir ve değerlendirebilir. Ayrıca, transformatörün enerji tüketimi, güç kalite analizleri gibi değerler kontrol edilebilir. Karar verme planlarının bilgisi fiziksel güç transformatörüne geri gönderilir. Bu arada, karar verme sonucu daha sonra ihtiyaç duyulabilecek ürün bilgi kütüphanesini güncellemek için de kullanılabilir [10].

\section{PLM VE DİJITALLEŞME}

PLM şirketlerin rekabet avantajı elde etmeleri için müşterilere ek değerler sunmalarını sağlar. Ürün yaşam döngüsü genelinde üretilen ürün verilerini yöneterek PLM, iş süreçlerini daha verimli, esnek ve etkili hale getirir. Bir şirketin ürünle ilgili maliyetleri azaltmasını ve ürün kalitesini iyileştirmesini sağlar ve pazara sunma zamanını

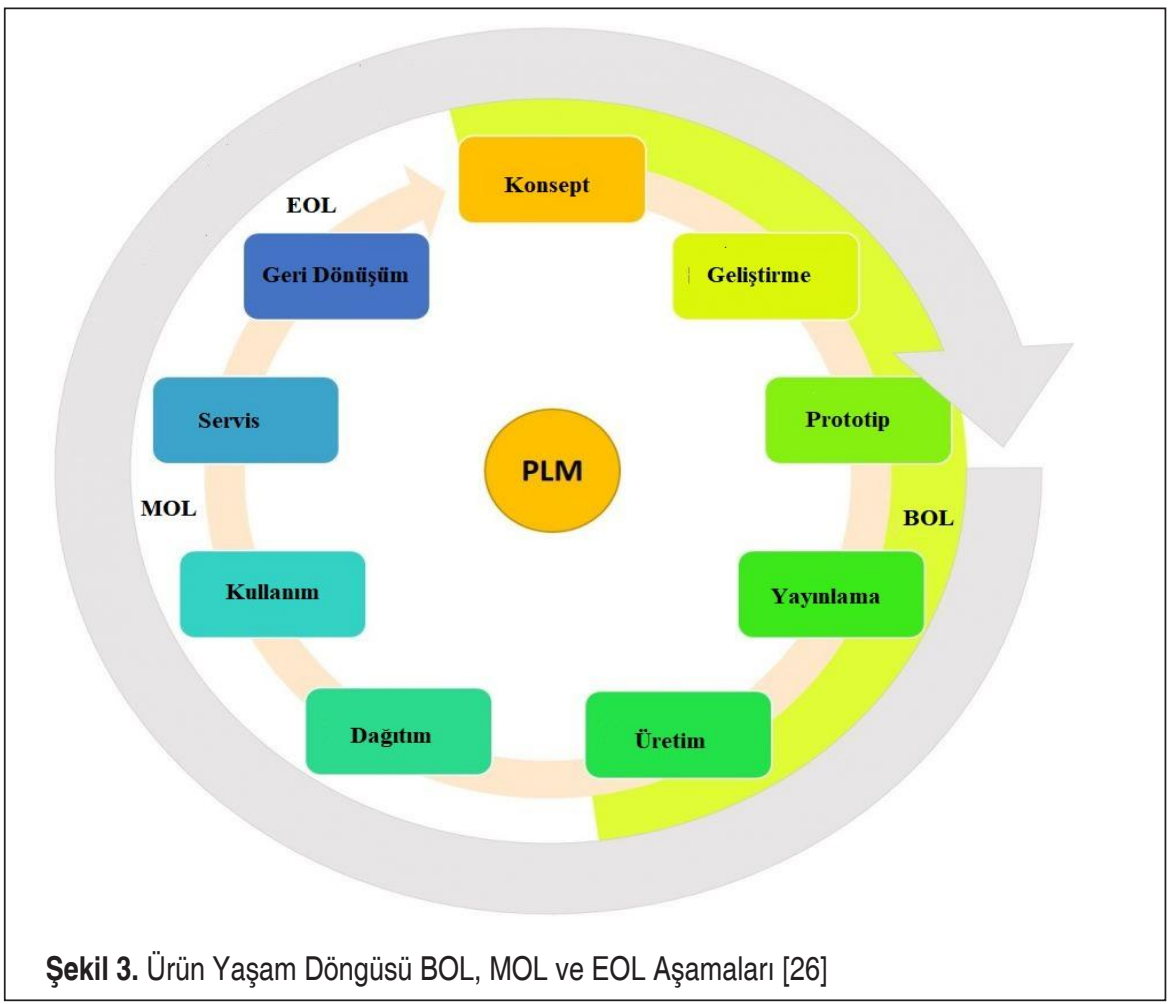


kısaltarak ve daha verimli ürünler sunarak müşteri memnuniyetini doğrudan arttırır ve pazar payını dolaylı olarak arttırır [6].

Şekil 3'te bir ürün ömrünü üç önemli aşamada kategorize edebildiğimiz gösterilmiştir. $\mathrm{Bu}$ aşamalar, kavramsallaştırma, tanımlama ve gerçekleştirmeyi içeren ömür başlangıcı (BOL) aşaması, kullanım, bakım ve servis de dâhil olmak üzere ömür ortası (MOL) aşaması, ürünün yenilenmesi ile yeniden kullanımı, parçaların sökülmesi ve yenilenmesi ile yeniden kullanımı, sökülmeden malzeme 1slahı, sökme ile malzeme ıslahı ve son olarak yakma ile birlikte veya bertaraf olmaksızın imha edilmesi gibi çeşitli senaryolarla karakterize edilen ömür sonu (EOL) aşamalarıdır [25].

PLM geleneksel olarak fiziksel ürün verilerinin toplanmasına odaklanır ve ürün üreticileri BOL aşamasından sorumludur. Bu nedenle MOL ve EOL aşamalarındaki ürün bilgileri ve bilgi akışı büyük ölçüde tutarsız ve eksiktir. Ürün yaşam döngüsündeki bu eksik bilgiler üreticilerin bütünsel bir ürün ve hizmet sağlama kapasitelerini sınırlamaktadır.

Ayrıca, PLM'de ürün verilerinin yönetilmesini ve uygulanmasını etkileyen bazı sorunlar vardır. Mevcut uygulamalar, sanal modellerdeki verilerden ziyade fiziksel ürün verilerinin analizine ağırlık vermeyi tercih eder [10]. Ancak, bilgi teknolojilerinin uygulanması ile PLM'in zorlukları büyük ölçüde azaltabilir.

Ürünleri yaşam döngüsü üzerinden takip ederek, radyo frekansı tanımlama (RFID) teknolojisi ve Nesnelerin İnterneti (IoT) ile doğru, gerçek zamanlı ve eksiksiz ürün bilgileri ile ürünün bilgi döngüsü kapatılabilir [27]. Ürünler sensörler ile donatıld1ğından, üreticilerin MOL ve EOL aşamalarında ürün verilerini toplaması ve bu verileri gelecekte ürünü geliştirmek için kullanması mümkündür. IoT teknolojisi ile ürün yaşam döngüsündeki hammadde, bileşen, makine, ürün ve tesisler gibi her şey entegre akıllı cihazlarla donatılabilir.

Dijitalleşme ile ürünün yaşam döngüsü hakkında gerçek zamanlı veriler alınarak kapalı çevrim yaşam döngüsü yönetimini mümkün kılar. Kapalı çevrim yaşam döngüsü yönetimi ile ürünlerin tasarım, üretim, kullanımı ve ömür sonu geri dönüşüm aşamalarının sürekli olarak geliştirilmesi sağlanır. O yüzden kapalı çevrim PLM ile tüm ürün ömrü boyunca bilgiler toplanır. Bunun sonucunda ürün kalitesi iyileştirilebilir. Nihayetinde, MOL ve EOL operasyonları BOL'deki ürün tasarımı ve üretimle ilgili bilgiler kullanılarak kolaylaştırılabilir. Tasarımcılar ve mühendisler tarafından alınan BOL kararları, sağlanan MOL ve EOL bilgilerinin yardımıyla daha doğru olacaktır [28]. Ayrıca, işletmelerin yöneticilerinin operasyon ve karar verme ile ilgili sorunları çözmelerine yardımcı olabilir.

Ürün yaşam döngüsünün her aşamasında, PLM'in ulaşmak istediği hedefler farkl1dır. BOL aşaması ürün tasarımını ve üretim kalitesini geliştirmeyi hedeflerken, MOL aşaması ürünlerin güvenilirliği, kullanılabilirliği ve sürdürülebilirliğini iyileştirme 
ile ilgilidir. $\mathrm{Bu}$ nedenle, dijitalleşmenin farklı ürün yaşam döngüsü fazlarında PLM üzerindeki etkisi farklı olduğundan hareketle dijitalleşmenin sırasıyla BOL, MOL ve EOL'de PLM fazları üzerindeki etkisi açıklanmıştır.

\subsection{Dijitalleşmenin BOL Fazındaki Etkileri}

Yukarıda belirtildiği gibi, tüm bu aşamalarda veri ve bilgi oluşturulmuştur. BOL'un tasarım ve üretim aşamaları arasında veri ve bilginin oluşturulması CAD / CAM / CAE ve diğer simülasyon yazılımları gibi akıllı sistemler tarafından desteklenir. Ürün Veri Yönetimi (PDM), birçok OEM tarafından ve etkileri yoluyla tedarikçilerince etkili ve verimli bir şekilde kullanılmaktadır. Ürün tasarımı verilen sorunlara çözüm bulmaya odaklanırken, imalat tasarımı somutlaştırmaya odaklanmaktadır. PLM'in bakış açısından, dijitalleşme ile üretim süreci gerçek zamanlı olarak izlenebilir ve ölçülebilir, karmaşık kalite sorunlarının nedenleri sorunlara dönüşmeden önce bulunabilir [4].

İlk olarak, dijitalleşme ürünleri ve süreç geliştirmeyi geliştirir. Sensör teknolojileri, üretim sürecini iyileştirmek için ürünün gerçek zamanlı durum bilgisini sağlayabilir. Sanal fabrika aracılığıyla bir şirket üretim sürecini gerçek zamanlı olarak izleyebilir, kontrol edebilir ve risklere hazırlanabilir. Sanal prototipleme ile sistem planlamacıları üretim sürecindeki değişikliklere hızlı bir şekilde yanıt verebilir, takım ve süreç tasarımının esnekliğini ve verimliliğini geliştirebilir ve BOL aşamasında kullanılabilirlik, konfor ve güvenlik açısından insan-makine etkileşimini göz önünde bulundurabilir. Fabrikadaki gerçek fiziksel kaynaklara kadar uzanan üç boyutlu simülasyonlar ile tasarımcılar, üretim süreçleri ve mevcut kaynakların bilgisi ve bağlamı ile tasarım yapabilir, böylece ürün geliştirme süreçlerinin hızlı ve hassas bir şekilde modellenmesini sağlayabilir [29].

İkinci olarak, dijitalleşme ürünün piyasaya sürülme süresini azaltmaya yardımcı olur. Üretim sırasında ortaya çıkan hataların \%85'i tasarım aşamasında karar verme ile ilgili olduğundan, ürün tasarımı çok önemlidir [30]. Dijital bir fabrikada bir bilgi sistemi kullanarak, ürün yaşam döngüsünde meydana gelen beklenmedik problemlerden kaçınılabilir ve bu nedenle ürün tasarım projesinde zamandan tasarruf edilebilir ve son olarak ürünün piyasaya sürülme süresi azaltabilir. BOL'da grafiksel kullanıcı ara yüzü (GUI) ve artırılmış gerçeklik (AR) kullanılarak, gerekli kâğıt çizimlerinin sayısı azaltılabilir ve tasarım revizyon aşaması hızlandırılabilir, böylece 'eşzamanlı mühendislik' gerçekleştirilir ve piyasaya sürülme süresi kısalır.

Üçüncüsü, dijitalleşme BOL aşamasında daha iyi enerji yönetimini destekleyebilir. IoT ile hammadde tedarikini, ürünün simülasyonunu optimize ederek ve tasarım aşamasında üretim ekipmanlarının verimli çalışma düzenini ayarlayarak daha iyi enerji yönetimi sağlanabilir. Üretim aşamasında enerji yönetimi üretim süreçlerinin daha iyi izlenmesi ve kontrol edilmesiyle başarılabilir. Örneğin, test verileri ürün yaşam döngüsü sırasında otomatik ekipmanlar tarafından üretilir, daha sonra teknoloji uzmanları 
veya tasarımcılar, farklı etki faktörleri ile bağlantılı test verilerinin ilişkisini analiz ederek karar verebilir ve en enerji verimli ürün tasarımını seçebilirler [31].

\subsection{Dijitalleşmenin MOL Fazındaki Etkileri}

Ürün geliştirme bakış açısından, araştırmalar çoğunlukla BOL aşamasına odaklanır ve dağıtım, kullanım ve destek gibi MOL aşamasına ilişkin bilgiler eksiktir. Ömür boyu maliyeti optimize etme veya yüksek değerli veya uzun ömürlü ürünlerin kullanılabilirliğini arttırma gereksinimleri nedeniyle, üreticilerin sadece sözleşme sürecindeki dönem boyunca ürün performansını garanti etmeleri değil, aynı zamanda bakım hizmetini de sağlamaları beklenmektedir [32].

Geleneksel olarak, ürünler fabrikadan taşındığında ve müşterilere teslim edildiğinde, ürünlerin sahibinin üretici yerine müşteri olarak değiştiği kabul edilir. Makineler veya ekipmanlar son kullanıcılar tarafından kullanıldığında, ilgili verileri toplamak ve analiz etmek zordur. Bu nedenle, üreticinin ürün kullanım verilerini kullanarak ürünü iyileştirmesi, çalışmayı optimize etmesi ve müşterilerin ürünü yüksek verimlilikte kullanması da zordur. Dijitalleşme yardımıyla teknik olarak ürünleri internete bağlamak ve bir IP adresi atamak mümkündür, böylece birbirleriyle, diğer bileşenlerle ve hatta uzaktan kumandalarla iletişim kurabilir ve etkileşime geçebilirler. Bu nedenle, verimli nakliye planlaması, optimize edilmiş depo yönetimi, kapsamlı enerji kullanım kılavuzu, öngörücü ve önleyici bakım yoluyla bu engeller ile başa çıkmamızı sağlar [31].

Dijitalleşmenin MOL fazında PLM üzerindeki bir diğer etkisi de ömür boyu maliyeti azalmasına yardımcı olmasıdır. Dijitalleşmenin en önemli faydalarından biri, planlanmamış arıza riskini azaltmak, yedek parçalar için envanter seviyesini azaltmak ve hatta yedek parçaların kullanılabilirliğini planlayarak envanter maliyetini en aza indirmek için planlanabilecek önleyici bakımı mümkün kılmaktır [32].

Akıllı buzdolabını ürününü örnek olarak kullanırsak, dijitalleşmenin MOL aşamasında enerji verimliliği ve proaktif bakım sağlayabileceği gösterilmiştir. Enerji verimliliğini etkileyen anormal koşullar neredeyse gerçek zamanlı olarak tespit edilebilir, böylece zamanında düzeltilebilir ve örneğin uzaktan izleme yardımı ile yedek parçalara ihtiyaç duyulduğu zaman gecikmeden hazırlanabilir. Daha da önemlisi, tekrar eden ziyaretlerden kaçınmak için gereken yedek parçalar ve gerekli tedarik zamanı önceden belirlenebilir [33].

\subsection{Dijitalleşmenin EOL Fazındaki Etkileri}

Hızla tükenen doğal kaynaklar ve imalat sanayinin getirdiği istenmeyen çevresel sonuçlar ve sosyal sorunlar nedeniyle, artık kullanım sonu ürünlerle başa çıkmak için uygun stratejiler düşünülmeli ve geliştirilmelidir. EOL aşaması yeniden kullanım, geri dönüşüm, yeniden üretim ve imha ile ilgilidir. Şu anda, PLM'in birincil odakları BOL ve MOL fazlarıdır, EOL fazı üzerinde çok az çalışma vardır [6]. PLM'yi bir döngü ha- 
line getirmek ve kullanım sonu ürünlerin çevre ve insan üzerindeki olumsuz etkilerini azaltmak için EOL aşamasına değinmek gerekir. Tüm ürün yaşam döngüsü boyunca BOL'den MOL ve EOL'a geçerek, ürün bilgi akışı gittikçe daha az tamamlanır ve bu da EOL'de karmaşık karar verme süreçlerine yol açar. Bununla birlikte, her bir öğenin gerçek zamanlı ürün yaşam döngüsü verileri dijitalleşme, özellikle IoT yardımıyla izlenebilir, tespit edilebilir, saklanabilir ve analiz edilebilir. Böylece, son kullanım ürünleri ile ilgili kritik bilgiler, özellikle bu ürünlerin kalitesi ve kalan değeri tahmin edilebilir; dolayısıyla kaynak tasarrufu sağlayan geri dönüşüm faaliyetleri arttırılabilir [33].

Örnek olarak RFID tabanlı bir demontaj karar verme sistemi kullanılarak dijitalleşmenin EOL fazında PLM üzerindeki etkisi açıkça gösterilebilir [34]. Şu anda, geri dönüşüm şirketleri ürünleri topladıklarında, doğru ürün yaşam döngüsü bilgisi elde etmek zordur. Böyle bir sistemi kullanarak, geri dönüşüm firmaları her koşulda doğru ve zamanında yaşam döngüsü bilgisi sağlayabilir, böylece karar verme maliyeti azaltılabilir ve karar vermenin doğruluğu ve etkinliği artar. Sonuç olarak, geri kazanım verimliliği artırılabilir, çevre kirliliği en aza indirilebilir ve geri dönüş kazançları en üst düzeye çıkarılabilir.

\section{SONUÇLAR}

COVID-19 salgını ve gelişen teknoloji ile birlikte artık dijitalleşmenin firmalar için bir tercih değil zorunluluk olduğunu ifade etmek mümkündür. Çalışma kapsamında dijitalleşme, dijital ikiz kavramı ve uygulamalarına yer verilmiş ve ürün yaşam döngüsünde etkilediği aşamalar açıklanmıştır. Daha sonra PLM ve dijitalleşme ilişkisinden bahsedilerek, dijitalleşmenin ürün başlangıç (BOL), ürün ortası (MOL) ve ürün sonu (EOL) aşamalarında olan etkileri açıklanmıştır. Dolayısı ile anlamlı bir dijitalleşmenin PLM ile mümkün olacağ1 ve dijitalleşme ile PLM'in birbirini tamamlayan kavramlar olduğundan hareketle COVID - 19 ile başlayan sürecin PLM konseptinin yaygınlaşması ve farkındalığının artması için bir firsat olduğunu belirtmek mümkündür [35].

COVID-19 sonrası "yeni normalleşme” ile birlikte dijital kanalları kullanmakta geciken firmaların büyük ölçüde dezavantajlı olacakları değerlendirilebilir. Halihazırda dijitalleşmenin PLM üzerindeki etkisi devam etmektedir ve şirketlerin dijital çağda kendilerini rekabetçi tutmak için bazı adımlar atmaları gerekmektedir. Günümüzde, MOL ve EOL aşamasında ürünle etkileşimde bulunan birçok aktör, diğer aktörlerle çok az bilgi alışverişi yaparak yalnızca ilgili faaliyetlerini gerçekleştirmektedirler. Ek olarak dijitalleşme ile birlikte tasarımcılar, üreticiler, müşteriler ve geri dönüşümcüler gibi farklı elemanlar arasında bütünsel bir bilgi alışverişi ve etkileşim teşvik edilmektedir. Bunun gibi karmaşık ağa sahip organizasyonlarda iç ve dış kaynaklardan gelen bilgileri ortaklaşa kullanmak, yönetmek ve paylaşmak oldukça zorlayıcı olacaktır ve 
bu yüzden tamamlayıcı alanlarda uzmanlaşmış şirketlerle yapılacak ortaklıklar önemli olacaktır. Bu nedenle gelecekte tüm bu taraflar arasında güçlü bir ortaklığın gerekli olacağı öngörülmektedir [32].

Çalışmada ürün yaşam döngüsündeki sorunları çözmek için, dijital ikizin ürün tasarımı, ürün imalatı ve ürün hizmetinde yüksek potansiyel uygulamasına sahip olduğu sonuçlarına varılmıştır. Dijitalleşmeyle birlikte ürünlerin, süreçlerin karmaşıklığı artmaktadır ve veri hacmi son derece büyük hale gelmektedir ayrıca veri biçimlerinin çeşitliliği artmaktadır. Bu da verilerin yönetilmesinin daha zor hale gelmesine neden olmaktadır. PLM, çok büyük miktarda verinin verimli bir şekilde işlenmesini sağlamaktadır. Dijitalleşme ve dijital ikiz uygulamaları ile birlikte, imalat firmaları ve ilgili taraflar hem siber hem de fiziksel dünyada giderek daha fazla birbirine bağlanacaktır. Farklı alanlardan gelen veriler arasındaki bağlantıları modellemek için standartlaştırılmış ve endüstri genelinde kabul edilmiş PLM veri modelleri sağlamak imalat firmaları açısından oldukça önemlidir.

Teknoloji ve PLM ne kadar gelişmiş olursa olsun, süreçler insanlar tarafından yönetildiği, kontrol edildiği, uygulandığı ve gerçekleştirildiği için insanlar her zaman vazgeçilmezdir. Dijitalleşme nedeniyle karmaşıklık, soyutlama ve problem çözme becerilerine ve çok disiplinli bilgiye sahip insanlara olan ihtiyaç da artacaktır. Buna hazırlıklı olmak için özel eğitim verilmesi şirketler için bir seçenek olabilir. Gelecekte, PLM'in, malzeme geri dönüşümünde iyileştirmeyi, ürün ve lojistikte kapsamlı izlenebilirliği ve PLC genelinde kaynak kullanımının verimliliğini sağlayarak daha az kaynak yoğun bir toplum sağlaması beklenmektedir [6].

İleride yapılacak çalışmalarda araştırmacıların endüstri odaklı olarak dijitalleşme ve PLM etkileşimini gösteren vaka çalışmaları yapmaları önerilmektedir.

\section{KAYNAKÇA}

1. Gartner, 2016. "Gartner IT Glossary, "https://www.gartner.com/en/information technology/glossary/ digitalization, son erişim tarihi: 09.09.2020.

2. Herterich, M. M., Uebernickel, F., \& Brenner, W. 2015. "The Impact of Cyber-Physical Systems on Industrial Services in Manufacturing, Procedia Cirp, 30, p. 323-328, doi: 10.1016/j.procir.2015.02.110.

3. Figay, N., Ghodous, P., Khalfallah, M., Barhamgi, M. 2012. Interoperability Framework for Dynamic Manufacturing Networks. Computers in Industry, 63(8), pp.749-755, doi: 10.1016/j.compind.2012.08.008.

4. Parviainen, P., Tihinen, M., Kääriäinen, J., Teppola, S. 2017. "Tackling the Digitalization Challenge: How to Benefit from Digitalization in Practice, "International Journal of Information Systems and Project Management., vol.5., p.63-77, doi: 10.12821/ijispm.

5. Golovatchev, J.D., Budde, O. 2007. June. Next Generation PLM-an integrated approach 
for the Product Lifecycle Management. In Dans Proceedings of ICCPR2007: International Conference on Comprehensive Product Realization 2007. Proceedings of ICCPR2007: International Conference on Comprehensive Product Realization.

6. Terzi, S., Bouras, A., Dutta, D., Garetti, M., Kiritsis, D. 2010. "Product lifecycle management - From its history to its new role, "International Journal of Product Lifecycle Management, vol.4, p.360-389, doi: 10.1504/IJPLM.2010.036489.

7. Xin, Y., Ojanen, V. 2017. "The Impact of Digitalization on Product Lifecycle Management: How to Deal with it?, "IEEE International Conference on Industrial Engineering and Engineering Management (IEEM), 10-13 Aralık 2017, Singapore, doi: 10.1109/ IEEM.2017.8290062.

8. McKinsey. 2020. "COVID-19 US Digital Sentiment Survey, "https://www.mckinsey. com/business-function-s/marketing-and-sales/our-insights/survey-us-consumer-sentiment-during-the-coronavirus-crisis, son erişim tarihi: 09.09.2020.

9. Deloitte. 2020. "Küresel COVID-19 Salgınının Türkiye'de Farklı Kategorilere Etkileri, " https://www2.deloitte.com/tr/tr/pages/consulting/articles/kuresel-covid-19-salgininin-turkiyedefarklikategorilereetkileri.html, son erişim tarihi: 09.09.2020.

10. Tao, F., Cheng, J., Qi, Q., Zhang, M., Zhang, H., Sui, F. 2018. "Digital Twin-driven product design, manufacturing and service with big data , "The International Journal of Advanced Manufacturing Tech $\neg$ nology, vol. 94, p. 3563-3576, doi: 10.1007/s00170017-0233-1.

11. Baig, A., Hall, B., Jenkins P., Lamarre, E., McCarthy, B. 2020. "The COVID-19 Recovery Will be Digital: A Plan for the First 90 days, "https://www.mckinsey.com/business-functions/mckinsey-digital/our-insights/the-covid-19-recovery-will-be-digital-aplan-for-the-first-90-days, son erişim tarihi: 16.06.2020.

12. Lundin, N. 2020. "Covid-19 and digital transformation - What do we see now and what will we see soon?, "https://sweden-science-innovation.blog/beijing/covid-19-and-digital-transformation-what-do-we-see-now-and-what-will-we-see-soon, son erişim tarihi: 09.09.2020

13. Grant J. 2019. "Where Does PLM Fit in Digital Transformation?, https://www.designnews.com/ automation-motion-control/where-does-plm-fit-digital-transformation, son erişim tarihi: 09.09.2020.

14. Hess, T., Matt, C., Benlian, A., Wiesböck, F. 2016. "Options for Formulating a Digital Transformation Strategy, "MIS Quarterly Executive, vol.15, p.123-139, doi: 10.4324/9780429286797-7.

15. Grieves, M. 2014. "Digital twin: manufacturing excellence through virtual factory replication, "http://www.apriso.com/library, son erişim tarihi: 09.09.2020.

16. Bolton, R. N., McColl, K., Janet, R., Cheung, L., Gallan, A., Orsingher, C., Witell, L., Zaki, M. 2018. "Customer experience challenges: Bringing together digital, physical and social realms, "Journal of Service Management, vol.29, no. 5, p. 776-808.

17. Tuegel, E., Ingraffea, A.R., Eason, T.G. 2011. "Reengineering aircraft structural life 
prediction using a digital twin, "International Journal of Aerospace Engineering.,vol.11, p. 1-14, doi: 10.1155/2011/154798.

18. Smarslok, B., Culler, A., Mahadevan, S. 2012. "Error quantification and confidence assessment of aerothermal model predictions for hypersonic aircraft. "53rd AIAA/ASME/ ASCE/AHS/ASC Structures, Structural Dynamics, and Materials Conference, 23-26 Nisan 2012, Honolulu, Hawaii, doi: 10.2514/6.2012-1817.

19. Cerrone, A., Hochhalter, J., Heber, G. ve Ingraffea, A. 2014. "On the Effects of Modeling as-manufactured Geometry: Toward Ddigital Twin, "International Journal of Aerospace Engineering, DOI: 10.1155/2014/439278.

20. Mussomeli,A., Meeker, B., Shepley, S., Schatsky, D. 2018. "https://www2.deloitte. com/us/en/insights/focus/ signals-for-strategists/understanding-digital-twin echnology. html, son erişim tarihi: 09.09.2020.

21. Boschert, S., Rosen, R. 2016. "Digital Twin-the Simulation aspect, Mechatronic Futures, Springer International Publishing, Switzerland, doi: 10.1007/978-3-319-32156-1_5.

22. Glaessgen, E., Stargel, D. 2012. "The digital twin paradigm for future NASA and US Air Force vehicles, "53rd AIAA/ASME/ASCE/ AHS/ASC Structures, Structural Dynamics and Materials Conference, 23-26 Nisan 2012, Honolulu,Hawaii.

23. Tao, F., Bi, L.N., Zuo Y., Nee, A.Y.C. 2016. "A Hybrid Group Leader Algorithm for Green Material Selection with Energy Consideration in Product Design, "CIRP Annals Manufacturing Technology, vol.65, p. 9-12, doi: 10.1016/j.cirp.2016.04.086.

24. Qi, Q., Tao, F., Hu, T., Anwer, N., Liu, A., Wei, Y., Wang, L., Nee, A. 2019. "Enabling Technologies and Tools for Digital Twin, "Journal of Manufacturing Systems, 2019, p 1-19, doi: 10.1016/j.jmsy.2019.10.001.

25. Ötleș, S., Üçok, B. 2018. "Kapalı Döngü - Ürün Yaşam Döngüsü Yönetimi, "Plastik ve Ambalaj Teknolojisi Dergisi, s. 45-54.

26. Smartsheet. 2020. "The New Product Development Process and Product Life Cycle Management, "https://www.smartsheet.com/product-life-cycle-management, son erişim tarihi: 09.09.2020.

27. Li, J., Tao, F., Cheng, Y., Zhao, L. 2015. "Big Data in Product Lifecycle Management", "The International Journal of Advanced Manufacturing Technology", 81(1-4), 667-684, doi: 10.1007/s00170-015-7151-x.

28. Kiritsis, D. 2013. "Semantic Technologies for Engineering Asset Life Cycle Management, "International Journal of Production Research", vol.51, p. 7345-7371, doi: 10.1080/00207543.2012.761364.

29. Kuo, C.F., Wang, M.J. 2012. "Motion Generation and Virtual Simulation in a Digital Environment, "International Journal of Production Research, vol. 50, no. 22, p. 65196529, doi: 10.1080/00207543.2011. 653698 .

30. Affonso R.C., Cheutet V., Ayadi M., and Haddar M. 2013. "Simulation in product lifecycle: Towards a better information management for design projects, "Journal of Modern Project Management, vol. 1, no. 1, p. 113-119.

31. Tao, F., Wang, Y., Zuo, Y., Yang, H., Zhang, M. 2016. "Internet of Things in Prod- 
uct Life-Cycle Energy Management, "Journal of Industrial Information Integration, doi: 10.1016/j.jii.2016.03.001.

32. Roy, R., Stark, R., Tracht, K., Takata, S., Mori, M. 2016. "Continuous Maintenance and the Future - Foundations and Technological Challenges, CIRP Annals - Manufacturing Technology, vol. 65, p.667-688.

33. Främling, K., Holmström, J., Loukkola, J., Nyman, J., Kaustell, A. 2013. "Sustainable PLM through Intelligent Products, "Engineering Applications of Artificial Intelligence, vol. 26. p. 789-799, doi: 10.1016/ j.engappai.2012.08.012.

34. Chen, S., Yi, J., Zhu, X., Jiang, H., Ju, W. 2017. "RFID-based Integrated Method for Electromechanical products disassembly decision-making, "International Journal of Computer Integrated Manufacturing, vol. 30, no. 2-3, p. 229-254, doi: 10.1080/0951192X.2016.1145807

35. Ellenrieder, S. 2017. "No meaningful Digitalization Without PLM, "https://www. plmportal.org/en/no-mea-ningful-digitalization-without-plm.html, son erişim tarihi:09.09.2020. 